\title{
Conditioned Taste Aversion Diminishes Sugar Intake
}

\author{
Alma Gabriela Martínez Moreno, Antonio López-Espinoza, Imelda de León López, \\ Laura Vanesa Solano Santos, Fernando Hernández-Leonardo \\ Behavioral Feeding and Nutrition Research Center, CUSur, University of Guadalajara, Ciudad Guzmán, México \\ Email: alma.martinez@cusur.udg.mx
}

Received 14 March 2014; revised 14 April 2014; accepted 21 April 2014

Copyright (C) 2014 by authors and Scientific Research Publishing Inc.

This work is licensed under the Creative Commons Attribution International License (CC BY). http://creativecommons.org/licenses/by/4.0/

c) (i) Open Access

\begin{abstract}
Animals learn to avoid particular food when some of its sensory properties are associated with gastrointestinal discomfort. Twenty rats were exposed to free access to food and a sugar solution for ten days in first phase. During second phase, experimental group received a dose of LiCl. Control group received an injection without $\mathrm{LiCl}$. Both groups had free access to a sugar solution and food restriction for three days. In the final phase, both groups returned to the conditions of first phase. Results showed a significant decrease in sugar intake after aversive conditioning regarding the intake registered in the initial phase in experimental group. Control group did not show any differences in its sugar intake before and after the experimental manipulation. The procedure carried out is discussed as a means to decrease sugar intake.
\end{abstract}

\section{Keywords}

Sugar, LiCl, Conditioned Taste Aversion, Rats

\section{Introduction}

Animals learn to avoid food when some of its sensory properties are associated with gastrointestinal discomfort [1]-[3]. Conditioned taste aversion (CTA) is effective for the survival of the organisms, since it prevents from a repetitive consumption of toxic substances available in the environment [4].

In the behavioral laboratory, conditioning to rejection to food by administering different substances which cause evident signs of physical discomfort has been shown [5]. The procedure is as follows: a substance-unconditioned stimulus (US) — which causes physical discomfort—or an unconditioned response (UR)—is associated to a food that is habitually consumed. After a few trials, the customarily consumed food-now a conditioned stimulus (CS)—is rejected by the subject producing a conditioned response (CR) by associating food to the feeling 
of discomfort [6]. Schafe and Bernstein [7] pointed out that the decisive characteristic of CTA is the presence of certain selective associability. In other words, acquiring a CR depends on the association of a specific stimulus (taste) with a specific effect (signs of gastrointestinal disorder or nausea).

The simplest experimental procedure to generate aversive conditioning to food lies in having a taste and inducing the gastrointestinal discomfort afterwards. The association of stimulus produces a rejection towards that taste (from a change in its hedonic value) which is susceptible in measurement: grams or milliliters consumed after the procedure in comparison to measurement of these variables before the procedure [8].

The substances which have been employed in experimental situations to induce an aversion to a certain food are considerable [9]-[12]. Often Lithium Chloride ( $\mathrm{LiCl})$ is used [13]-[15]; it is administered through intraperitoneal injections. After five to ten minutes, symptoms caused by the $\mathrm{LiCl}$ appear: the animal remains motionless, its peristalsis increases and an increase in activity to certain stimulus can be observed. The limitations in the use of this substance lie in control of duration of the effects produced after administering it. How is it possible to know that the effect of the substance or procedure has begun or ended? Bures [16] described that in specific case of $\mathrm{LiCl}$, the duration of the symptoms begin after ten minutes of applying it, it reaches its peak action between one and two hours later to disappearing after ten hours have gone by after the injection.

It has been documented that the effect of the $\mathrm{LiCl}$ on food intake, with which it has been associated with during classic conditioning, is so effective that one trial is enough to observe even its extinction [10]. However, in the case of sweetened solutions, this procedure has been used only in few studies. Archer and Sjödén [17] showed that the association between administering an intra-peritoneal injection of LiCl with various contexts gave way to decrease saccharine sweetened solution intake. Peck and Ader [18] also demonstrated that it is possible decrease saccharine sweetened solutions intake when a group of rats was exposed to deprivation conditioning followed by exposure to saccharine and an intra-peritoneal injection of cyclophosphamide (a substance that causes nausea and gastrointestinal discomfort). Nevertheless, these studies used saccharine, an artificial sweetener which does not contain calories. In the case of sweeteners with calories, a study carried out by Nachman and Ashe [19] concluded that the association between several doses of $\mathrm{LiCl}$ and a solution at $15 \%$ sucrose produces an aversive conditioning to the sweet taste successfully. Various groups of rats were exposed to several doses of $\mathrm{LiCl}$ by intra-peritoneal, subcutaneous or through a tube connected directly to the stomach. The LiCl dose was applied in ascending manner to part of subjects and in descending manner to the other part. Results showed that efficiency of the procedure depended exclusively on the amount of administered LiCl and not on the available solution, manner of administering, or the order in which the dose was presented.

Loy and Hall [20] also confirmed that it is possible to show aversion to sucrose after administering LiCl. They exposed a group of rats to a salt and sucrose compound previous to $\mathrm{LiCl}$ intake. They found that the animals showed an aversion to sucrose and concluded that the $\mathrm{LiCl}$ is an effective substance to establish feeding aversions.

In view of the above, the question arose if CTA is effective to observe a decrease, or even, a rejection to sugar solutions intake. As it has been described in various studies it is well known that animals prefer the sweet taste over others in varied experimental procedures [21] [22]. It has also been described that it is difficult for animals to decrease sugar intake voluntarily. Explanation for this behavior falls under three main arguments: 1) animals have an innate attraction towards sweet taste [23], 2) that energetic content of nutritional sweeteners conditions these preferences [24]-[26], and 3) combination of both components determines its preference over other foods [27]. For this reason, the general purpose of this research consisted in measuring the effects of administering $\mathrm{LiCl}$ intra-peritoneal injection in relation to sugar solutions intake, with purpose of showing if the CTA may be effective when it comes to a sweet tasting substance and energetic content like sugar. Specific objectives included: 1 ) to compare the registered sugar intake throughout a base line with consumption during CTA procedure, 2) to compare sugar intake of experimental group with control group not exposed to CTA, and 3) to determine number of trials that are sufficient to observe the decrease in the intake of sweetened solution during experimental phase. In addition, weight and food intake variables were measured before and after applying CTA procedure.

\section{Methods and Materials}

\subsection{Subjects}

Wistar rats $(n=20)$ from the vivarium at the South Campus of the University of Guadalajara were used. Their 
body weight ranging between 230 and $250 \mathrm{~g}$ at the start of the experiment. The rats were singly housed in a vivarium under a $12: 12 \mathrm{~h}$ light-dark cycle at $21^{\circ} \mathrm{C}$ and were fed powered chow (Purina Chow No. 5001 pellets). Also, sugar solutions at $8 \%$ were used. LiCl solutions were prepared (Mallinckrodt, Lab Guard) for each of the animals in the experimental group. The dosage depended on the weight of the animal $(3.0 \mathrm{mEq} / \mathrm{kg}$, just as it was done in the Nachmanand Ashe study [19]). All the procedures in the present study were performed in accordance to the principles outlined by the Mexican Official Norm (NOM-062-ZOO-1999), Technical Specifications for the Production, Care and Use of Laboratory Animals.

\subsection{Procedure}

Subjects were assigned at random into two groups: experimental group $(\mathrm{N}=10)$ and control group $(\mathrm{N}=10)$. Experimental group remained on a base line for ten days: 24 hours of free access to food and sugar solution at 8\% (first phase). At the end of the ten days, subjects were exposed to three days of experimental phase: free access to sugar solution and food restriction. Immediately, they were given the LiCl (second phase). After this period of time, animals went back to base line conditions for ten days (final phase). Control group was exposed to the same procedure except that the injection did not contain any substance.

\subsection{Data Analysis}

Individual comparisons were evaluated using simple main effects or t-tests when appropriate. Statistical analysis was performed with SPSS software (version 18.0 SPSS Inc., Chicago, IL, USA).

\section{Results}

Figure 1 shows sugar intake during the whole experiment. It was observed that experimental group decreased sugar intake during final phase in regards to registered intake in first phase. Control group showed the same pattern of sugar intake during first and final phase. Both groups registered an average sugar intake of $105 \mathrm{ml}$ during second phase. T-student test shows significant difference in sugar intake between the control group and the experimental group only during phase $3(\mathrm{p}=0.00109)$.

Figure 2 shows the mean and deviated standard of sugar intake from experimental and control groups compared to first phase (base line, before the CTA) regarding final phase (following the CTA). Experimental group consumed $150 \mathrm{ml}$ during first phase and $70 \mathrm{ml}$ during final phase, while control group consumed an average of $145 \mathrm{ml}$ during these phases. Statistical analysis demonstrated that sugar intake decreased significantly in experimental group during final phase in regards to the registered intake during first phase $(p=0.00294)$. Control group did not show significant difference between these phases ( $\mathrm{p}=0.99489)$.

Figure 3 shows the daily register of food consumption for experimental group (black circles) and control group (white circles). A significant statistical difference was not observed in the registered food consumption between both groups ( $p=0.12799$ ). In the same way, differences in food consumption between first and last phase were not observed. Both groups consumed an average of $15 \mathrm{~g}$ during these phases. Food intake during

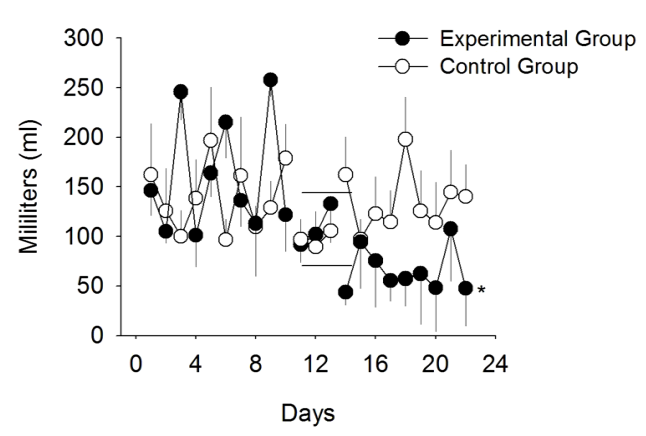

Figure 1. Daily register of sugar intake. Shows the mean and standard deviation of the daily register of sugar intake during the 23 days the experiment lasted. The horizontal lines emphasize the three days that CTA was applied. Sugar intake decreased significantly in experimental group after CTA. 


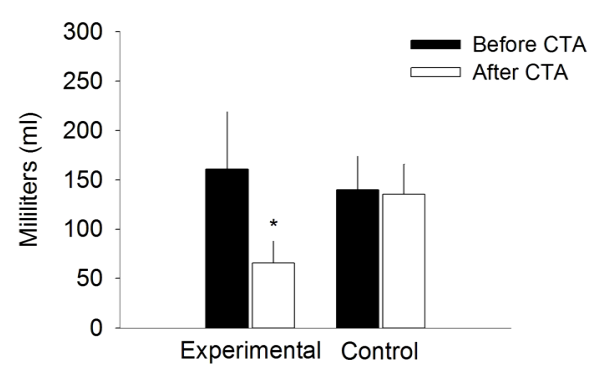

Figure 2. Sugar intake before and after CTA. Mean and standard deviation of sugar intake during first (before the CTA) and final phase (after the CTA). Sugar intake decreased significantly only in experimental group.

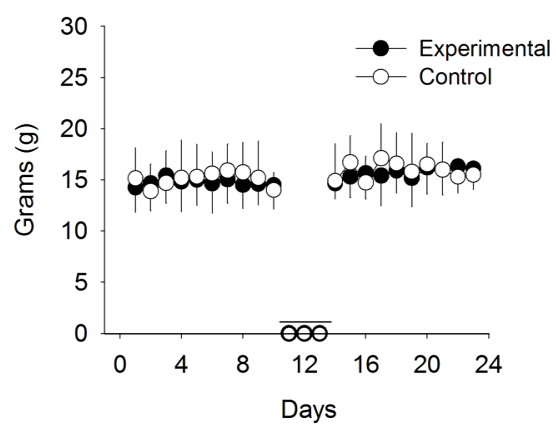

Figure 3. Food intake. Shows the mean and standard deviation of food intake. No significant differences were observed between the groups $(\mathrm{p}=0.99575)$.

second phase (CTA) is at zero stressed by the horizontal line because the animals only had the sugar solution available.

Finally, Figure 4 shows the daily register of body weight. In general, it was observed that both groups demonstrated the same pattern: they decreased their body weight during the application of the CTA in regards to the registered body weight during initial phase, which was recovered gradually during last phase. The range of registered body weight during first phase was placed between 240 and $260 \mathrm{~g}$, it gradually decreased during second phase from 240 to $220 \mathrm{~g}$ and it was recovered in a rising manner starting at $230 \mathrm{~g}$ until reaching $250 \mathrm{~g}$ again during final phase. In this last phase, experimental group recovered its body weight much faster than control group, but as of the seventh day, the body weights from both groups were matched. No significant differences were observed between the groups $(\mathrm{p}=0.99575)$.

\section{Discussion}

General purpose of this research was to evaluate the effect of applying $\mathrm{LiCl}$ on sugar solution intake, with the intention of demonstrating if the association of this with an aversive conditioning can affect its consumption. Results showed that experimental subjects decreased an average of $80 \mathrm{ml}$ of sugar solution intake after experimental sessions in which the CTA was applied in comparison to consumption during the first phase, whereas the controlled did not show differences in the consumption of the sugar solution before or after the CTA. Therefore, it is possible to state that experimental manipulation (CTA) had an effect on consumption of sugar solution.

Based on previous evidences, it was expected that the subjects would stop consuming sugar solutions [3] [4]. Ballesteros et al. [5] stated that only one trial can be enough to establish an aversive conditioning to food (whichever the case) that was associated to discomfort. It has also been expressed that an aversive conditioning to a specific taste may result resistant to extinction and remains [6]. In the case of the present investigation, the sugar consumption after the experimental sessions decreased but none of subjects interrupted its consumption. This result may be explained with three arguments. First is related to the procedure used. Possibly, the applied dose was not enough to establish an aversive conditioning to sugar indefinitely. The increase of the LiCl dose may 


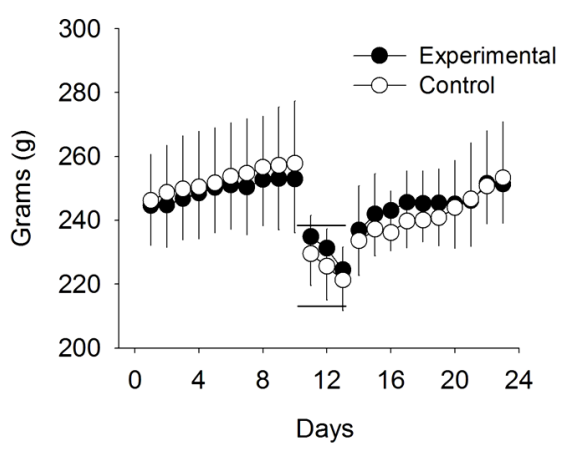

Figure 4. Body weight. Shows the mean and standard deviation of body weight. The horizontal lines emphasize the three days the CTA was applied (Phase 2).

assure a greater effect on intake manipulation. However, this condition could affect the behavior of subjects and their consumption of any other food, depending on the discomfort it would produce. For this reason, the dose used in other experiments was employed. This is determined by the animal's body weight [19].

A second argument also includes the procedure that was used. In the present investigation an A-B-A experimental design was applied. It is likely that the duration of this design would provide with relevant data to the subject matter of this study. That is, to replicate once more the A-B condition. This may allow us to clarify the continuous decrease in sugar consumption, or its recovery. Nevertheless, this possibility could also result dangerous to animals feeding, since an extra injection of $\mathrm{LiCl}$ could produce other results that are not necessarily due to sugar consumption.

Finally, the third argument refers to the characteristics of the food that is used. In previous studies, aversive conditioning was established to specific flavors that do not have postingestive consequences [18]. In this case, the sugar has a sweet taste and calories. This condition could make it harder to establish an aversive conditioning. Houpt, Zahorik and Swartzman-Ander [28] demonstrated that aversive conditioning is harder to establish with sweetened food in comparison to other foods. They used horses to which they associated the state of discomfort to foods like alfalfa, pellets, corn, and sweet foods. They associated the food to an immediate state of discomfort to one part of the subjects, while for the others this state was induced after 30 minutes had gone by. Results showed that a rejection to food was observed when an immediate state of discomfort was induced in comparison to the subjects that were induced to the discomfort 30 minutes later. However, they observed that in both cases more sweet food was consumed in regards to the rest of the manipulated foods. This allows us to conclude that the availability of sugar makes it harder to establish the aversion because of its qualities.

Perhaps the use of sweet taste without calories may produce a more conclusive outcome than the one obtained in our results. Peck and Ader [18] showed that animals may reject saccharine sweetened beverages when induced to an aversive conditioning. They associated doses of saccharine solution followed by the state of discomfort. Subjects used were in conditions of deprivation or satiation. The authors concluded that by using a highly palatable saccharine solution it was possible to observe the aversion conditioning in satiation conditions. This observation has been shown by other authors [29].

Another point of interest lies on the first specific objective of this investigation: to compare sugar sweetened solution intake during base line (Phase 1) with the consumption during the CTA. A rising pattern of sugar consumption was observed in experimental subjects during the CTA application which merely reached the registered mean during base line. This being the only food available during the experimental sessions, this situation determined the presence of this pattern. Control group showed a similar consumption pattern. Just as Schafe and Bernstein [7] describe it, for there to be a taste aversion, a certain selective associability must first exist. That is, that the response acquisition seems to depend on the association of a specific stimulus (taste) with a specific consequence (gastrointestinal alteration or nauseas), which could explain the alteration in consumption of this solution after manipulation, since the substance was able to provoke discomfort in the subjects.

A second specific objective of this investigation was to compare the intake of a sweetened solution from experimental group with the intake of that same solution in a control group which was not exposed to the CTA. No differences were observed in sugar intake registered during first phase in both groups: pattern consumption was 
similar to that reported in other studies in which an "up and down" pattern was described [30] [31]. During second phase, both groups decreased their sugar intake in regards to the one registered during initial phase. Results in final phase showed that experimental subjects demonstrated an obvious decrease, while the controlled recovered immediately their sugar intake and matched it to the one registered in first phase. This leads us to conclude that there was a successful association between sugar intake and the discomfort produced by the $\mathrm{LiCl}$ injection. If this association would not have resulted, it is possible that experimental subjects would have increased their sugar intake just as control subjects. Even though the modification in sugar intake registered by experimental subjects was not expected (they were expected to interrupt the sugar intake completely) the association between substance and the discomfort produced by the $\mathrm{LiCl}$ injection seems to demonstrate that the procedure used allows to ensure modification in consumption behavior, such as it has been reported in other investigations [14].

The final specific objective was to determine the number of sufficient trials to be able to observe a decrease in the consumption of the sweetened solution during base line after experimental manipulation. In this research three $\mathrm{LiCl}$ injection trials were used, while in other studies there have been reports of learning exposure to only one trial [5] [29]. None of experimental subjects interrupted their sugar intake. These findings suppose that the quality of food impeded to obtain this result, just like it was mentioned before. Another possibility lies in the dosage of available sugar. Parker and MacLeod [30] pointed out the effectiveness of associating LiCl with a sucrose solution at 20\%. The dose of sugar used in this investigation was 8\%. Martínez, López-Espinoza and Martínez [31] described that the greater the concentration of sugar the lower the consumption in comparison to a lesser concentration of sweeteners. For this reason, the possibility exists that a higher concentration of the sweet taste by itself may result to be aversive.

Other results obtained from the dependent variables which were also measured, include food intake and body weight. Regarding food intake, no differences were observed between previous phases or following the application of the CTA procedure. During the CTA animals were food deprived. These results reinforce the hypothesis that CTA procedure was successful at associating the state of discomfort only with the sugar. This way, most of the feeding preferences to tastes are not predetermined, but can be related to certain types of experiences. In the particular case of this investigation, experimental subjects did not associate food with the state of discomfort provoked by the LiCl injection, on the contrary it would have been revealed in food consumption that was registered.

One last measured dependent variable was the body weight of the subjects. Within the averages obtained a decrease in body weight was observed: experimental subjects weighed an average of $248 \mathrm{~g}$, in experimental sessions of $232 \mathrm{~g}$, and by the third phase they showed an average of $243 \mathrm{~g}$. The consulted literature on aversive conditioning does not report modifications in the body weight of the manipulated subjects.

\section{Conclusion}

In conclusion, our results showed a decrease in sugar solution intake through the association of a discomfort produced by the $\mathrm{LiCl}$ injection. It is important to admit that an aversive condition to taste is important to all organisms, since it prevents the repeated consumption of toxic or harmful substances available in the environment [2]. Sugar intake is not always harmful: depending on the diet and the amount of consumption. It has been shown that laboratory animals develop an addictive pattern when they have sugar available, and that they even come to prefer the calories of a sweetener more than the calories of nutritive food. For this reason, it would be useful to generate an experimental procedure to decrease sugar consumption, or rather control their intake.

\section{Acknowledgements}

Research financed by CONACYT (CB_101314, Scholarship 16488).

\section{References}

[1] Garb, J.L. and Stunkard, A.J. (1974) Taste Aversions in Man. AmericanJournal of Psychiatry, 131, 1204-1207.

[2] García, E. and Bach, L. (1999) Preferencias y Aversiones Alimentarias. Anuario de Psicología, 30, 55-77.

[3] Bernstein, I.L. (1991) Flavor aversion. In: Getchell, T.V., Doty, R.L., Bartoshuk, L.M. and Snow, J.B., Eds., Smell and Taste Health and Disease, Raven Press, New York, 417-428. 
[4] Molero, A. (2007) Aprendizaje Aversivo Gustativo: Características, Paradigma y Mecanismos Cerebrales. Anales de Psicología, 23, 57-64.

[5] Ballesteros, M.A., Gallo, M. and Maldonado, A. (2001) Detección de aversiones gustativas inducidas por estímulos incondicionados débiles como la rotación. Psicológica, 22, 217-234.

[6] García, J. and Koelling, R.A. (1966) Relation of Cue to Consequence in Avoiding Learning. Psychonomic Science, 4, 123-124. http://dx.doi.org/10.3758/BF03342209

[7] Schafe, G.E. and Bemstein, I.L. (1996) Taste Aversion Learning. In: Capaldi, E.D., Ed., Why We Eat What We Eat, American Psychological Association, Washington, 31-51.

[8] Díaz, E., De la Casa, L.G., Ruiz, G. and Baeyens, F. (2004) Aprendizaje sabor-sabor en la adquisición de preferencias gustativas. Psicológica, 25, 135-146.

[9] Garcia, J., Lasiter, P.S. and Bermúdez-Rattoni, F. (1985) A General Theory of Aversion Learning. Annals of the New York Academy of Sciences, 443, 8-21. http://dx.doi.org/10.1111/j.1749-6632.1985.tb27060.x

[10] Schafe, G.E., Sollars, S.I. and Bemstein, I.L. (1995) The CS-US Interval in Taste Aversion Learning: A Brief Look. Behavioral Neuroscience, 109, 799-802.

[11] Eccles, S., Kim, E.M. and O’Hare, E. (2005) Granisetron Attenuates Exercise-Induced Conditioned Taste Aversion in the Rat. Appetite, 44, 325-328. http://dx.doi.org/10.1016/j.appet.2005.02.001

[12] Masaki, T. and Nakajima, S. (2005) Further Evidence for Conditioned Taste Aversion Induced by Forced Swimming. Physiology \& Behavior, 84, 9-15. http://dx.doi.org/10.1016/j.physbeh.2004.09.022

[13] Goudie, A.J. (1979) Aversive Stimulus Properties of Drugs. Neuropharmacology, 18, 971-979. http://dx.doi.org/10.1016/0028-3908(79)90161-8

[14] Parker, L.A., Hills, K. and Jensen, K. (1984) Behavioral CRs Elicited by a Lithium- or an Amphetamine-Paired Contextual Test Chamber. Animal Learning \& Behavior, 12, 307-315. http://dx.doi.org/10.3758/BF03199972

[15] Bernstein, I.L. and Borson, S. (1986) Learned Food Aversion: A Component of Anorexia Syndromes. Psychologiocal Review, 94, 462-472. http://dx.doi.org/10.1037/0033-295X.93.4.462

[16] Bures, J. (1998) Ethology, Phiysiological Psychology, and Neurobiology of CTA. In: Bures, J., Bermúdez-Rattoni, F. and Yamamoto, T., Eds., Conditioned Taste Aversion: Memory of a Special Kind, Oxford University Press, New York, 14-25. http://dx.doi.org/10.1093/acprof:oso/9780198523475.003.0002

[17] Archer, T. and Sjödén, P. (1979) Positive Correlation between Pre- and Postconditioning Saccharin Intake in TasteAversion Learning. Animal Learning \& Behavior, 7, 144-148. http://dx.doi.org/10.3758/BF03209263

[18] Peck, J. and Ader, R. (1974) Illness-Induced Taste Aversion under States of Deprivation and Satiation. Animal Learning \& Behavior, 2, 6-8. http://dx.doi.org/10.3758/BF03199107

[19] Nachman, M. and Ashe, J.H. (1973) Learned Taste Aversions in Rats as a Function of Dosage, Concentration, and Route of Administration of LiCl. Physiology \& Behavior, 10, 73-78. http://dx.doi.org/10.1016/0031-9384(73)90089-9

[20] Loy, I. and Hall, G. (2002) Taste Aversion after Ingestion of Lithium Chloride: An Associative Analysis. The Quarterly. Journal of Experimental Psychology, 55b, 365-380. http://dx.doi.org/10.1080/02724990244000070

[21] Ackroff, K. and Sclafani, A. (2004) Fructose-Conditioned Flavor Preferences in Male and Female Rats: Effects of Sweet Taste and Sugar Concentration. Appetite, 42, 287-297. http://dx.doi.org/10.1016/j.appet.2008.05.059

[22] Ackroff, K., Manza, L. and Sclafani, A. (1993) The Rat’s Preferente for Sucrose, Polycose and Their Mixtures. Appetite, 21, 69-80. http://dx.doi.org/10.1006/appe.1993.1037

[23] Booth, D. (1990) Learned Role of Tastes in Eating Motivation. In: Capaldi, E.D. and Powley, T., Eds., Taste, Experience, and Feeding, American Psychological Association, Washington, 179-195. http://dx.doi.org/10.1037/10075-013

[24] Bolles, R.C., Hayward, L. and Crandall, C. (1981) Conditioned Taste Preferences Based on Caloric Density. Journal of Experimental Psychology: Animal Behavior Processes, 7, 59-69. http://dx.doi.org/10.1037/0097-7403.7.1.59

[25] Carper, J. and Polliard, F. (1953) A Comparison of the Intake of Glucose and Saccharin Solutions in Conditions of Caloric Need. American Journal of Psychology, 66, 479-482. http://dx.doi.org/10.2307/1418243

[26] Martínez, A.G., López-Espinoza, A., Díaz, F. and Valdés, E. (2009) Consumo de soluciones endulzadas en ratas albinas: Sabor vs calorías. Psicothema, 21, 196-203.

[27] Sclafani, A. (1990) Nutritionally Based Leamed Flavor Preferences in Rats. In: Capaldi, E.D. and Powley, T., Eds., Taste, Experience, and Feeding, American Psychological Association, Washington, 139-156. http://dx.doi.org/10.1037/10075-010

[28] Houpt, K.A., Zahorik, D.M. and Swartzman-Andert, J.A. (1990) Taste Aversion Learning in Horses. Journal of Animal Science, 68, 2340-2344.

[29] Parker, L.A. and Mac Leod, K.B. (1994) Chin Rub CRs May Reflect Conditioned Sickness Elicited by a Lithium-Pair- 
ed Sucrose Solution. Pharmacology, Biochemistry and Behavior, 40, 983-986. http://dx.doi.org/10.1016/0091-3057(91)90115-I

[30] Martínez, A.G. and López-Espinoza, A. (2007) Efectos post-privación con dos alternativas energéticas en ratas. Revista Mexicana de Análisis de la Conducta, 33, 43-60.

[31] Martínez, A.G., López-Espinoza, A. and Martínez, H. (2006) Efectos de modificar el contenido energético del agua sobre el peso corporal, consumo de agua, alimento y calorías en ratas. Universitas Psychologica, 5, 361-370. 